\title{
Chemical Warfare Agents Analyzer Based on Low Cost, Room Temperature, and Infrared Microbolometer Smart Sensors
}

\author{
Carlo Corsi, Andrea Dundee, Paolo Laurenzi, Nicola Liberatore, \\ Domenico Luciani, Sandro Mengali, Angelo Mercuri, Andrea Pifferi, Mirko Simeoni, \\ Gaetano Tosone, Roberto Viola, and Donatella Zintu
}

Centro Ricerche Elettro Ottiche, SS.17 Località Boschetto, 67100 L'Aquila, Italy

Correspondence should be addressed to Sandro Mengali, sandro.mengali@consorziocreo.it

Received 2 August 2012; Revised 26 September 2012; Accepted 26 September 2012

Academic Editor: Antoni Rogalski

Copyright ( 2012 Carlo Corsi et al. This is an open access article distributed under the Creative Commons Attribution License, which permits unrestricted use, distribution, and reproduction in any medium, provided the original work is properly cited.

\begin{abstract}
Advanced IR emitters and sensors are under development for high detection probability, low false alarm rate, and identification capability of toxic gases. One of the most reliable techniques to identify the gas species is absorption spectroscopy, especially in the medium infrared spectral range, where most of existing toxic compounds exhibit their strongest rotovibrational absorption bands. Following the results obtained from simulations and analysis of expected absorption spectra, a compact nondispersive infrared multispectral system has been designed and developed for security applications. It utilizes a few square millimeters thermal source, a novel design multipass cell, and a smart architecture microbolometric sensor array coupled to a linear variable spectral filter to perform toxic gases detection and identification. This is done by means of differential absorption spectroscopic measurements in the spectral range of the midinfrared. Experimental tests for sensitivity and selectivity have been done with various chemical agents (CAs) gases and a multiplicity of vapour organic compounds (VOCs). Detection capability down to ppm has been demonstrated.
\end{abstract}

\section{Introduction}

One of the most reliable techniques to identify the gas species is absorption spectroscopy in the medium infrared spectral range, where most of existing toxic compounds exhibit their strongest rotovibrational absorption bands $[1,2]$.

The present work will describe a compact point sensor for providing early warning in the presence of CAs in the air. Battlefields and urban areas at risk of terroristic attack were the foreseen application scenarios. Wide chemical range and effective identification of targets and rejection of other vapours were given as the key performance objectives.

The sensor is based on Active Multispectral Infrared Absorption Spectroscopy in the gas phase and uses 38 spectral channels to represent molecular fingerprints across the LongWave IR spectrum (LWIR).

The heart of the sensor is an advanced detector device that integrates microbolometers, optical filter arrays, and front-end electronics on silicon chip.

\section{Sensor System}

The sensor system essentially consists of an IR thermal source, a multipass optical cell, and an array of detectors and filters, plus electronics and software for signal readout, processing and analysis. Figure 1 shows a scheme of the sensor system. A description of the early design of the sensor system has been reported in [3].

The IR radiation emitted by the source is first modulated by a mechanical oscillator (to achieve improved $\mathrm{S} / \mathrm{N}$ by means of lock-in detection), then passed through the cell, (where it is attenuated by gas molecules at their IR resonant wavelengths), and, finally, focused onto the detector array (Figure 2). As the optical cell is in open air, the composition of the air in the sensor is the same as in the space around the sensor.

The thermal source is a commercial device made by a set of high emissivity thick-film filaments that can be heated up to around $1000 \mathrm{~K}$. Source modulation is provided by a taut band oscillator. Its working frequency $(7 \mathrm{~Hz})$ was selected to 


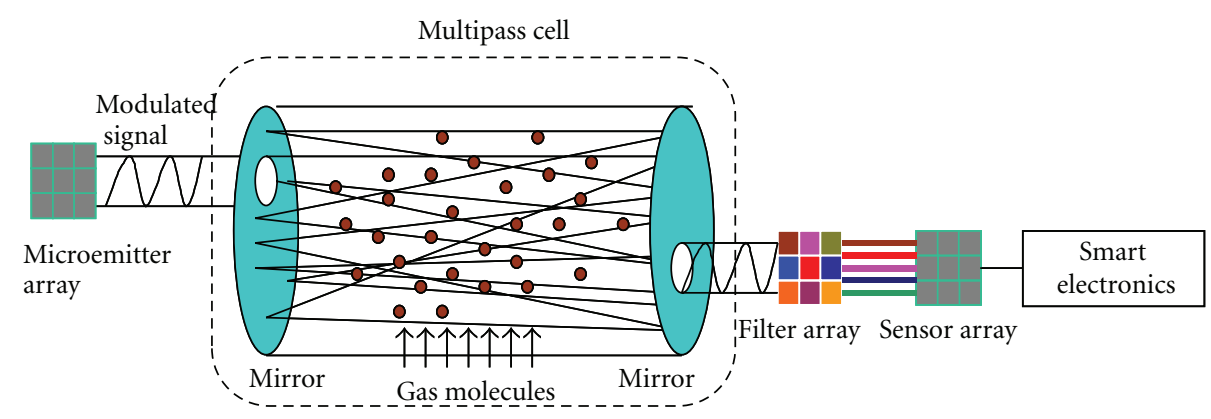

FIGURE 1: Scheme of the sensor system.

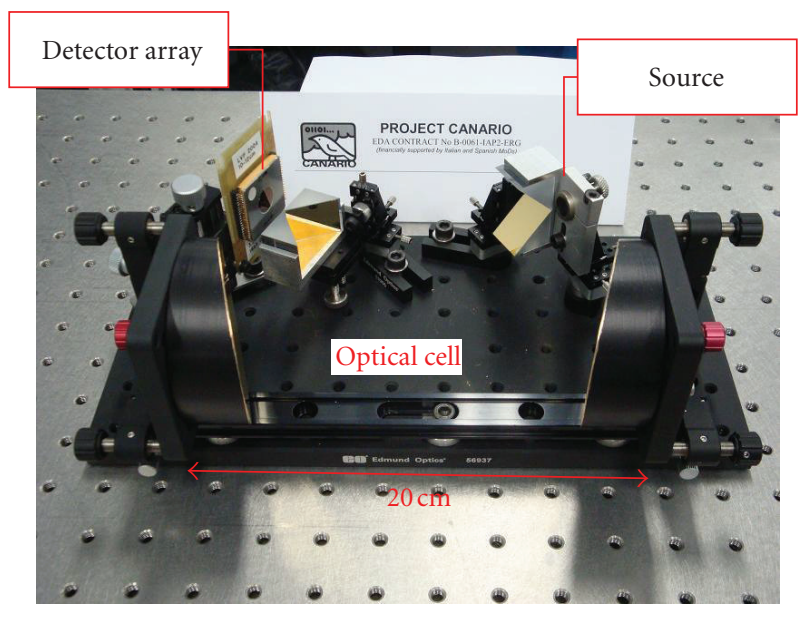

FIgURe 2: Optical cell.

match with the response time of the microbolometers. The optical cell [4] has been specifically designed to achieve high throughput efficiency with large entrance and exit apertures (to match the size of the hybrid detector array and the thermal source), long optical path, and compact volume.

In the technological demonstrator, a total of 38 microbolometers were arranged to fit in an area equal to the imagine of the source on the focal plane. Each pixel was closely coupled to a specific spectral filter and defines a specific spectral channel. All the spectral channels work in parallel to acquire an IR absorption spectrum.

The resolving power and the identification capacity of the system depend on the total number, position, and bandwidth, of the spectral channels. The final choice of the channels was made with the help of multivariate statistical analysis, by taking into account the spectral fingerprints of some 400 compounds [5], of which 20 were CAs, while the others were toxic industrial compounds (TICs) and VOCs of different nature and use. In its final configuration, the system spans the IR spectrum from 7.5 to 14 microns with an almost uniform spectral resolution of about $0.18 \mathrm{micron} / \mathrm{channel}$. This is sufficient to resolve the absorption bands of most CAs, but some problems may arise with blood agents such as $\mathrm{HCN}$, which have only one narrow $(\sim 0.08 \mu \mathrm{m})$ absorption peak at the edge of the sensor spectral window $(\sim 14 \mu \mathrm{m})$.
Simulations have shown identification failures when the system is tested with 10 s ppm of HCN.

For each spectral channel, absorption due to IR active vapours was calculated by comparing the signal to an average made over a set of previous acquisitions, used as background or reference. The background is a moving average that is continuously updated to account for drifts in the environmental conditions and in the air composition. As such, the system recognizes only spectral features that "pop up" in the timeframe of a few acquisitions (i.e., fast events as those due to accidents or attacks with CAs) and cannot be easily messed up by the presence of persistent gases.

\section{Detector Array}

Each microbolometer consists of an active layer of vanadium oxide (with its contacts) grown on a silicon nitride microbridge suspended over a silicon die (Figure 3(a)). Detectors are made with large area and specifically designed to optimize $\mathrm{S} / \mathrm{N}$ rather than spatial resolution or response time (as would be the case for an imaging array).

The detectivity $\left(D^{*}\right)$ of the microbolometers (Figure 3(b)), measured on a test bench, is higher than $1 \times 10^{8} \mathrm{~cm} \sqrt{\mathrm{Hz}} / \mathrm{W}$ at a modulation frequency of $7 \mathrm{~Hz}$ and in the whole spectral range $7-14 \mu \mathrm{m}$. As such, it is at the state of the art for this type of detectors. With an active area $(A)$ in excess of $1 \mathrm{~mm}^{2}$, the noise equivalent power of the detector (NEP $\left.=\sqrt{A} / D^{*}\right)$ is calculated better than $1 \times 10^{-9} \mathrm{~W} / \sqrt{\mathrm{Hz}}$. Since the system is designed to deliver to the detector an average in band power of several $\mu \mathrm{W}$, we could expect a signal-to-noise ratio $(\mathrm{S} / \mathrm{N})$ better than $10^{4}$ for an integration time of $10 \mathrm{~s}$. However, the measured $\mathrm{S} / \mathrm{N}$ of the sensor system was never found better than $10^{3}$, so demonstrating that detectors do not represent the bottleneck in sensitivity, and room exists to improve optical coupling efficiency and electronic noise.

Microbolometers were fabricated as linear arrays and closely coupled to linear variable (LV) interferential filters grown on independent substrate. The LV filters cover a major part of the LWIR spectrum, from 7.5 to 14 micron.

The same linear array was implemented into an hybrid device, which also includes four PbSe detectors, monolithically integrated with their corresponding interference filters, and working in the MWIR spectral range [6]. 
A printed circuit board (PCB) was designed and implemented for signal readout, lock-in amplification, and $A / D$ conversion of 38 electronic channels.

The integrated sensor (Figure 4) unit comprises room temperature arrays of microbolometers, filters, and, optionally, integrated electronics on silicon chips.

\section{Technological Demonstrator}

A technological demonstrator (Figure 5) has been constructed, consisting of a compact $\left(35 \times 25 \times 15 \mathrm{~cm}^{3}\right)$ sensor head, externally connected to a laptop computer and to software specifically developed for data analysis system control.

A dedicated human machine interface (HMI) has been developed to control the acquisition and data processing of the sensor.

Experimental spectra are acquired and displayed at a rate of $1 \mathrm{~Hz}$. Pattern recognition routines compare the measured spectrum to the already mentioned database of 400 compounds. In case of matching, the name of the compound is displayed on the computer screen together with its estimated concentration and reference spectrum (Figure 6). If the compound is a chemical agent (a "target"), the system delivers an alarm signal, while if it is not, the system just delivers a warning signal for the presence of an "interferent."

\section{Experimental Tests and Results}

Experimental tests were carried out with the sensor inside a glass box $600 \times 400 \times 300 \mathrm{~mm}$ and under a vapour tight steel lid (Figure 7). During the tests, the box was kept under an extraction hood as an additional safety measure.

The box featured heating elements and thermal control, to speed up vaporization and prevent recondensation of low volatile liquids. Use of fans favored air circulation and uniform distribution of the vapours in the air volume. Chemicals were injected as liquids through a silicone septum by means of a microsyringe. Other silicone ports were used to extract air samples from the box in the course of the test and analyze air composition by commercial GC Mass Spectrometer.

A short list of some representative compounds was selected to perform an acceptance test (AT). This list is reported in Table 1 . The tests were performed in the facilities of CETLI (Centro Tecnico Logistico Interforze) and no false negative or false positive were observed, while all the chemicals (both targets and interferents) were correctly detected and identified. Response time was in the order of a few seconds (anyhow depending on vaporization dynamics rather than on intrinsic response time of the sensor). Limit of detection (LoD) and limit of identification (LoI) depend on absorption coefficients (different for different chemicals) and on correlation thresholds (adjustable parameters). Values found for DMMP were LoD $\approx 900 \mathrm{ppb} ; \mathrm{LoI} \approx 7 \mathrm{ppm}$.

The system performance, during the tests with the substances in Table 1, is summarized in Table 2.
TABLE 1: List of compounds that have been used for the sensor validation.

\begin{tabular}{|c|c|}
\hline Substance name & Class \\
\hline Chloropicrin & Target (pulmonary agent) \\
\hline $\begin{array}{l}\text { Dimethyl methyl } \\
\text { phosphonate } \\
\text { (DMMP) }\end{array}$ & $\begin{array}{l}\text { Target (precursor and simulant } \\
\text { of nerve agent Sarin) }\end{array}$ \\
\hline 1,4-Thioxane & $\begin{array}{l}\text { Interferent (VOC, product of the } \\
\text { degradation of S-mustard) }\end{array}$ \\
\hline Triethyl-amine & $\begin{array}{l}\text { Interferent (VOC, chemical } \\
\text { analog of N-mustard) }\end{array}$ \\
\hline Isopropyl alcohol & Interferent (VOC) \\
\hline Ethanol & Interferent (VOC) \\
\hline Trichloroethylene & Interferent (TIC) \\
\hline Carbon tetrachloride & Interferent (TIC) \\
\hline
\end{tabular}

TABLE 2: System performance.

\begin{tabular}{|c|c|}
\hline $\begin{array}{l}\text { Chemical detection } \\
\text { range }\end{array}$ & All the 8 chemicals detected during AT. \\
\hline Sensitivity & $\begin{array}{l}\text { During AT, DMMP was found at LoD } \\
<900 \mathrm{ppb} \text { and LoI }<7 \text { ppm. } \\
\text { LoD and LoI depend on absorption } \\
\text { coefficients and on correlation } \\
\text { parameters settings. Typical values are } \\
\text { few ppm. }\end{array}$ \\
\hline Selectivity & $\begin{array}{l}\text { Very strong ability to recognize targets } \\
\text { and interferents. } \\
\text { All the } 8 \text { chemicals were correctly } \\
\text { identified during AT, by comparing the } \\
\text { experimental spectra to the full DB of } \\
400 \text { chemicals. }\end{array}$ \\
\hline Response time & Few seconds to detect the gas. \\
\hline False negative rate & No false negative during AT. \\
\hline False positive rate & No false positive during AT. \\
\hline $\begin{array}{l}\text { Size and power } \\
\text { needs }\end{array}$ & $\begin{array}{l}\text { Size } \approx 30 \times 20 \times 15 \mathrm{~cm} \text {; weight } \approx 7 \mathrm{Kg} \text {; } \\
\text { power }<15 \mathrm{~W} \text { (sensor head } \text {. }\end{array}$ \\
\hline
\end{tabular}

\section{Discussion}

The tests made with DMMP can be used to estimate with good accuracy the performance of the system against Sarin and other nerve agents of the $G$ and $V$ classes. Since the strength (alpha) and position (lambda_max) of the absorption peaks are so close for DMMP $\left(\alpha_{\mathrm{DMMP}}=2.7\right.$. $10^{-3} \mathrm{ppm}^{-1} \mathrm{~m}^{-1}$ at the wavelength $\lambda=9.52 \mu \mathrm{m}$ [7]) and Sarin $\left(\alpha_{\text {Sarin }}=3.0 \cdot 10^{-3} \mathrm{ppm}^{-1} \mathrm{~m}^{-1}\right.$ at the wavelength $\lambda=$ $9.88 \mu \mathrm{m}[8]$ ), the LoD for Sarin can be calculated as

$$
\operatorname{LoD}_{\text {Sarin }}=\operatorname{LoD}_{\mathrm{DMMP}} \cdot \frac{\alpha_{\text {Sarin }}}{\alpha_{\mathrm{DMMP}}} \approx 816 \mathrm{ppb} .
$$

Limits of detection in the $1 \mathrm{ppm}$ range can be expected also for the other $\mathrm{G}$ and $\mathrm{V}$ agents, since they all have absorption peaks in the range 9-11 micron and absorption strengths in the range $(1 \div 5) \cdot 10^{-3} \mathrm{ppm}^{-1} \mathrm{~m}^{-1}$. Similar considerations lead to estimate LoDs under 10 ppms for mustards as well. With this sensitivity, our sensor cannot be classified as a trace 


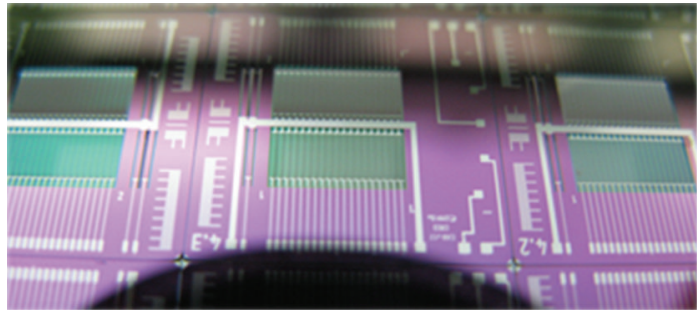

(a)

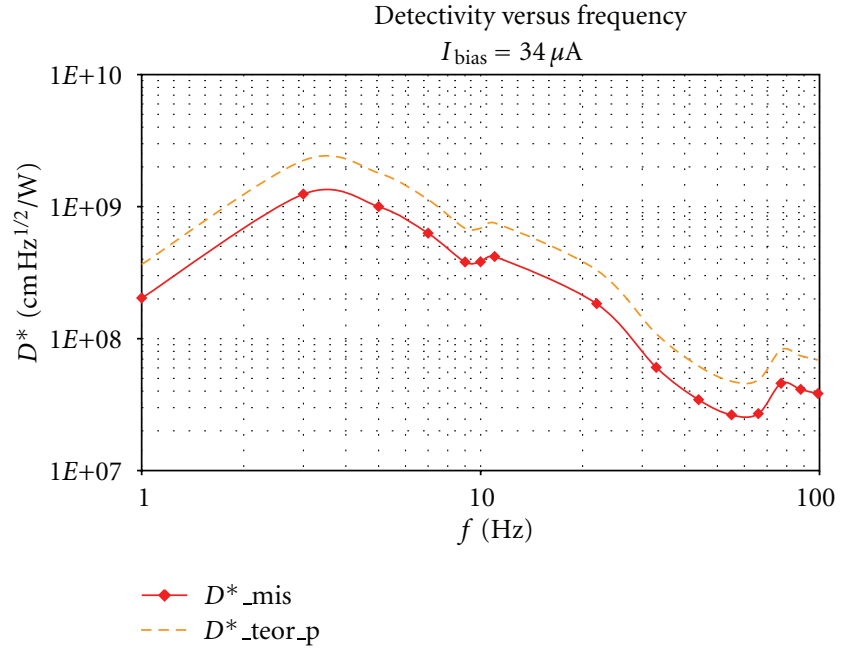

(b)

FIGURE 3: Application-designed VOx microbolometer arrays on SiN microbridges (a) and their detectivity (b).

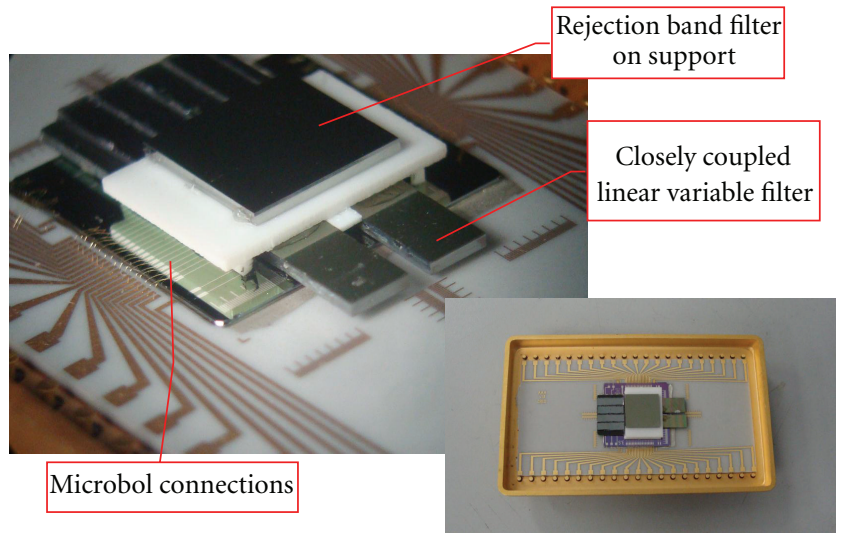

FIGURE 4: Integrated detector array.

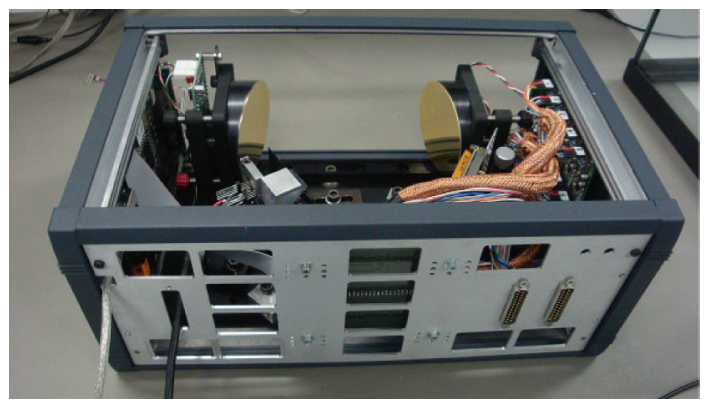

FIgURE 5: Technological demonstrator.

sensor suitable to detect CA agents at their minimum toxic or even lethal doses. However, its sensitivity is appropriate for early warning applications in real scenarios. In fact, in the course of a terroristic attack, the quantities of toxic agents released in the air would vastly exceed their lethal dose and could reach or even exceed their saturation concentration at the local temperature. Saturation concentration values of

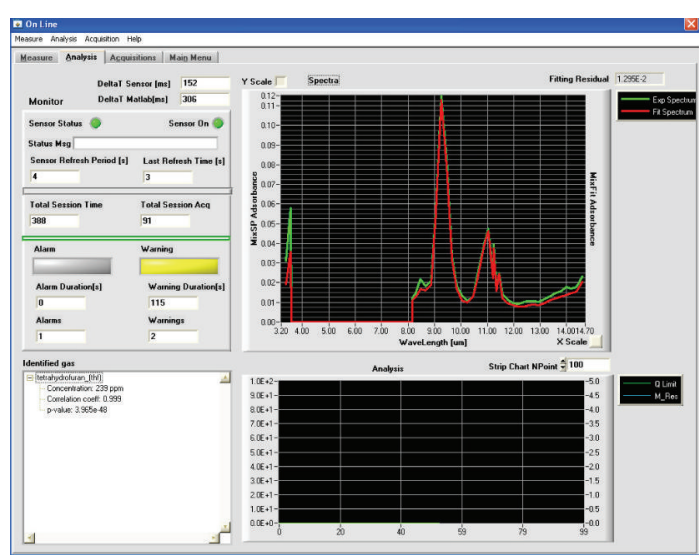

FIgURE 6: Results visualization.

Table 3 suggest that the sensor would deliver a prompt alarm in the presence of almost any CA, with the possible one 
TABLE 3: Saturation concentrations for some of the most common CAs.

\begin{tabular}{lccccccc}
\hline Substance name & $\begin{array}{c}\text { Tabun, GA } \\
\text { (nerve agent) }\end{array}$ & $\begin{array}{c}\text { Sarin, GB } \\
\text { (nerve agent) }\end{array}$ & $\begin{array}{c}\text { VX } \\
\text { (nerve agent) }\end{array}$ & $\begin{array}{c}\text { Sulfur mustard, H } \\
\text { (blister agent) }\end{array}$ & $\begin{array}{c}\text { Nitrogen } \\
\text { mustard, HN-1 } \\
\text { (blister agent) }\end{array}$ & $\begin{array}{c}\text { Lewisite } \\
\text { (blister agent) }\end{array}$ & $\begin{array}{c}\text { Diphosgene } \\
\text { (pulmonary } \\
\text { agent) }\end{array}$ \\
\hline $\begin{array}{l}\text { Saturation } \\
\begin{array}{l}\text { concentration in } \\
\text { the gas phase at }\end{array}\end{array}$ & 92 & 3289 & 1 & 92 & 329 & 461 & 13553 \\
\begin{tabular}{l}
$25^{\circ} \mathrm{C}(\mathrm{ppm})$ \\
\hline
\end{tabular} & & & & & & & \\
\hline
\end{tabular}

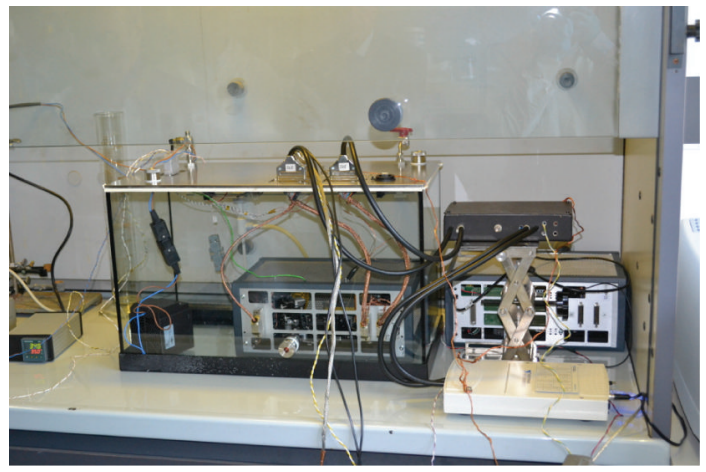

FIgURE 7: Experimental setup for the sensor validation.

exception of VX, that has a saturation concentration too low and too close to the LoD of the system.

\section{Conclusions}

A new design of advanced point sensor has been developed and validated, based on nondispersive Infrared (NDIR) absorption spectroscopy, capable of providing early warning in the presence of chemical agents or other toxic compounds in the air, and suitable for operation on battlefields or in urban areas at risk of terroristic attack.

Key assets of the sensor are its wide chemical range and strong selectivity. Results of repeated tests made over a wealth of chemical agents, solvents, perfumes, and other VOC, show that the sensor goes beyond the simple distinction between targets and interferents, as it is capable of correctly identifying chemicals selected from a list of 400 potential candidates.

With limits of detection and identification in the range from one to a few ppm, this sensor cannot be classified as a trace sensor according to nowadays standards. However, its sensitivity is appropriate for early warning in real scenarios, where the quantities of toxic agents released in the course of an attack would reach or even exceed the saturation concentration, which is generally higher than the lethal dose.

\section{Acknowledgments}

This work has been supported by the European Defence Agency (EDA) under the framework of the CANARIO (CWA Analyzer based on low cost dual band IR microsystems)
Project. CANARIO Project has been carried out in cooperation with Spanish Partners coordinated by ITM-CIDA Technological Institute.

\section{References}

[1] Y. Sun and K. Y. Ong, Detection Technologies for Chemical Warfare Agents and Toxic Vapors, CRC Press, 2005.

[2] M. E. Webber, M. Pushkarsky, and C. K. N. Patel, "Optical detection of chemical warfare agents and toxic industrial chemicals: simulation," Journal of Applied Physics, vol. 97, no. 11, Article ID 113101, pp. 1-11, 2005.

[3] C. Corsi, N. Liberatore, S. Mengali, A. Mercuri, R. Viola, and D. Zintu, "Advanced applications to security of IR smart microbolometers," in Proceedings of the International Society for Optical Engineering, vol. 6739 of Proceedings of SPIE.

[4] R. Viola, "High-luminosity multipass cell for infrared imaging spectroscopy," Applied Optics, vol. 45, no. 12, pp. 2805-2809, 2006.

[5] S. W. Sharpe, T. J. Johnson, R. L. Sams, P. M. Chu, G. C. Rhoderick, and P. A. Johnson, "Gas-phase databases for quantitative infrared spectroscopy," Applied Spectroscopy, vol. 58, no. 12, pp. 1452-1461, 2004.

[6] C. Sierra, S. Mengali, M. C. Torquemada et al., "Multicolor microbolometer and VPD PbSe hybrid focal plane sensors for analytical applications," in Proceedings of the 5th International Symposium on Optronics in Defence and Security (OPTRO '12), 2012.

[7] A. Mukherjee, I. Dunayevskiy, M. Prasanna et al., "Subparts-per-billion level detection of dimethyl methyl phosphonate (DMMP) by quantum cascade laser photoacoustic spectroscopy," Applied Optics, vol. 47, no. 10, pp. 1543-1548, 2008.

[8] S. W. Sharpe, T. J. Johnson, P. M. Chu, J. Kleimeyer, and B. Rowland, "Quantitative, infrared spectra of vapor phase chemical agents," in Proceedings of the Chemical and Biological Sensing IV, vol. 5085 of Proceedings of SPIE, August 2003. 

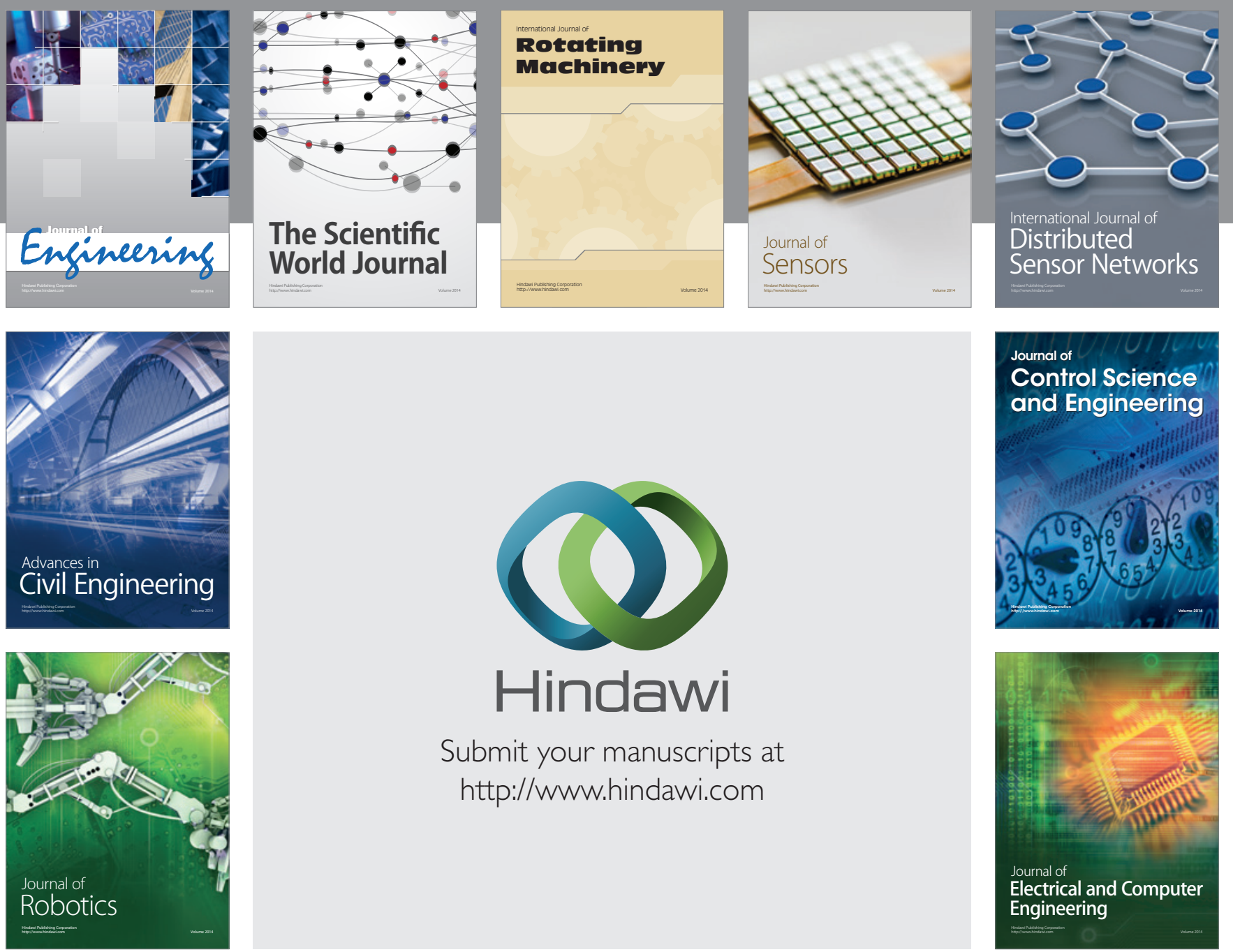

Submit your manuscripts at

http://www.hindawi.com
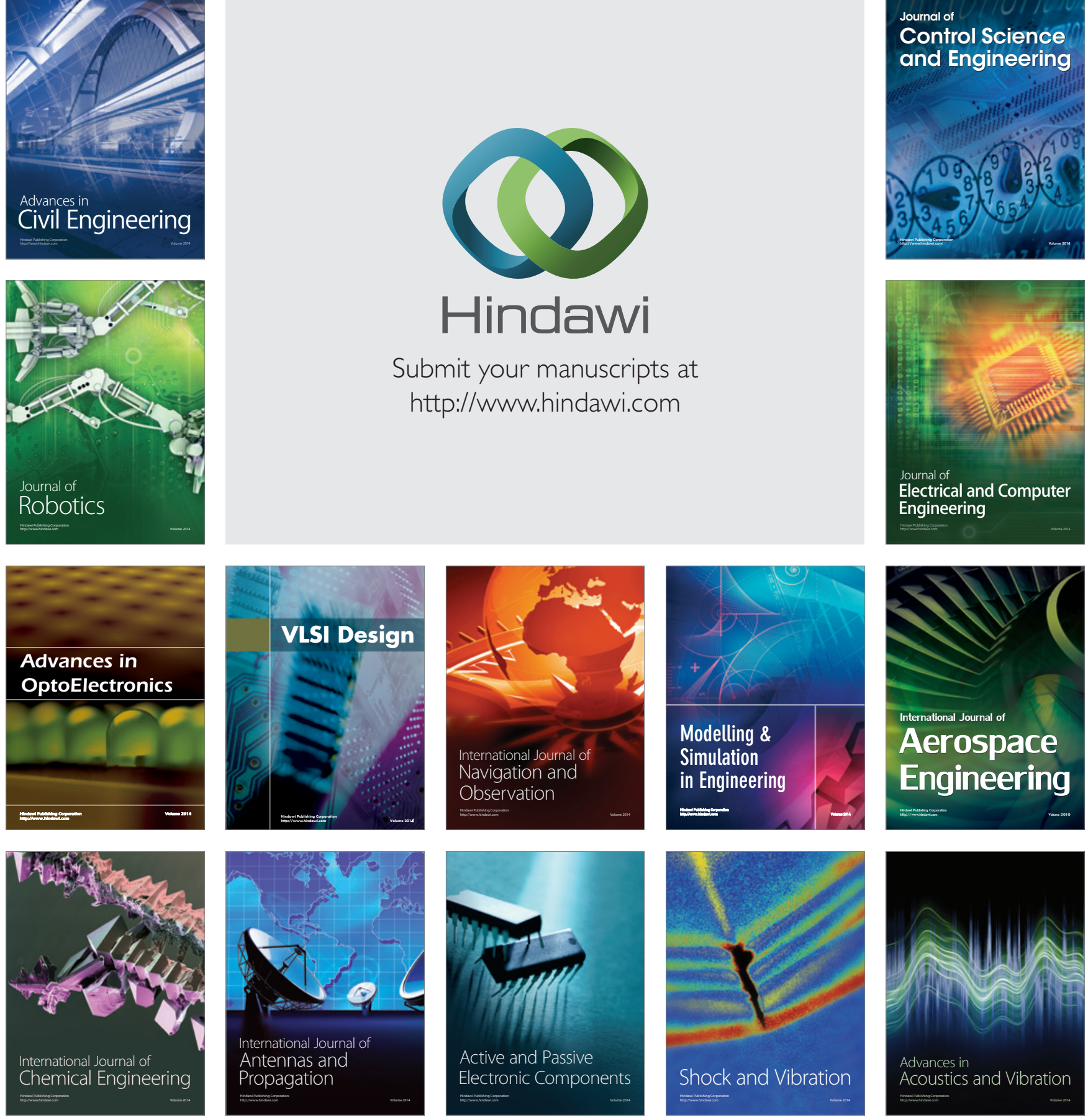